\title{
Receptor Activator of Nuclear Factor-Kappa Ligand and Osteoprotegerin Expressions on Hyperglycemic Wistar Rats (Rattus Novergicus) During Orthodontic Tooth Movement
}

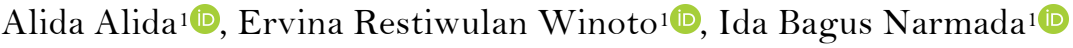

${ }^{1}$ Orthodontics Department, Faculty of Dental Medicine, Airlangga University, Surabaya, Indonesia.

Author to whom correspondence should be addressed: Alida, DDS., MSc., Orthodontics Department, Faculty of Dental Medicine, Airlangga University, Surabaya, Indonesia. Phone: +62315030255. E-mail: alida@fkg.unair.ac.id.

Academic Editor: Alessandro Leite Cavalcanti

Received: 15 February 2020 / Accepted: 02 June 2020 / Published: 22 July 2020

How to cite this article: Alida A, Winoto ER, Narmada IB. Receptor activator of nuclear factor-kappa ligand and osteoprotegerin expressions on hyperglycemic Wistar rats (Rattus Novergicus) during orthodontic tooth movement. Pesqui Bras Odontopediatria Clín Integr. 2020; 20:e0022. https://doi.org/10.1590/pboci.2020.145

\begin{abstract}
Objective: To investigate the differences of receptor activator of nuclear factor- $\kappa \mathrm{B}$ ligand (RANKL) and Osteoprotegerin (OPG) expressions between normoglycemic and hyperglycemic Wistar rats (Rattus Novergicus) during Orthodontic Tooth Movement (OTM). Material and Methods: This study was true experimental with post-test group only. Thirty-two healthy male Wistar rats, weighted around 200-250 grams, 12-20 weeks old, were used as OTM animal study. They were divided into 2 groups $(\mathrm{n}=16)$, normoglycemic rats (normal blood glucose $80-120 \mathrm{mg} / \mathrm{dl}$ ) and hyperglycemic rats $(>250 \mathrm{mg} / \mathrm{dl}$ ) induced by Streptozotocin with a dose of $30 \mathrm{mg}$ in PBS injection intraperitoneally. A NiTi closed coil spring was mounted between maxillary first molar and incisors with the light force $10 \mathrm{gf} / \mathrm{mm}^{2}$ in both groups to induce OTM. The studied animals were then terminated on days 1, 3, 6, and 9, respectively, and premaxilla was extracted. RANKL and OPG expression were examined utilizing immunohistochemistry (IHC) analysis. One-way ANOVA and Tukey HSD $(\mathrm{p}<0.05)$ were utilized to analyze the differences in the expression of RANKL and OPG between groups. Results: The hyperglycemic group on day 1, 9 rats showed a significant increase in the expression of RANKL, whereas OPG expression decreased significantly on days 1, 3, and 9. Conclusion: There was a significant increase of RANKL expression and a decrease of OPG expression in hyperglycemic rats as documented immunohistochemically.
\end{abstract}

Keywords: Diabetes Mellitus; Hyperglycemia; Orthodontics; Streptozotocin; RANK Ligand. 


\section{Introduction}

Age and medical history are important points that dentists should consider before starting any orthodontic tretament in hyperglycemic patients. A metabolic disorder is one of the highly considered conditions in patients prior to hyperglycemic that often occurs in daily practice such as hyperglycemia. Chronic hyperglycemia can cause various complications, and it is commonly caused by Diabetes Mellitus (DM) type I. The most commonly found case is that patients do not realize that they have DM; thus, most of them are found in clinics at an advanced stage, or this condition can arise after an orthodontic hyperglycemic is performed $[1,2]$.

The incidence of DM can occur in all age groups. The incidence of type I diabetes is usually found at the age of 14 years; therefore, DM type I is also called juvenile diabetes mellitus. In addition, the incidence of type II DM is usually found in patients aged 30 years and over, and the most commonly found are patients with an age range of 50-60 years. The number of people with type II DM covers about $90 \%$ of the total number of people with DM [3-5]. World Health Organization (WHO) reported that the number of people with DM in Indonesia would increase about $250 \%$ from 5 million in 1995 to 12 million in 2025. DM, as a chronic disease, can also cause bone metabolic disorder, which is a decrease in bone mass and quality [6,7].

One reported mechanism that explains the changes in bone remodeling in hyperglycemia is reduced bone formation due to decreased osteoblastic activity or increased apoptosis of osteoblasts and increased resorption activity in bone [8-10]. Changes in individual metabolism, which can interfere with bone remodeling, can produce the differences in the rate of orthodontic tooth movement (OTM) [11,12]. Even though the exact molecular mechanism is still not elucidated, hyperglycemia is considered may able to increase the production of macrophage colony-stimulating factor (MCSF), tumor necrosis factor- $\alpha$ (TNF- $\alpha)$, and receptor activator of nuclear factor-kappa ligand (RANKL), which are all crucial factors in proliferation and osteoclast differentiation [13,14]. Therefore, hyperglycemia may affect tooth movement during orthodontic hyperglycemic. The previous study found that the hyperglycemic condition in DM extends the duration of periodontal ligament degradation and alveolar bone resorption, where bone remodeling occurs in prolonged time $[2,15]$.

At the cellular level, bone remodeling consists of bone resorption at the compression area and bone formation in the tensile area. Several factors play a role in bone remodeling during OTM, one of which is a chemical mediator such as cytokines and growth factors that might affect osteoblasts and osteoclasts activity $[12,16,17]$. RANKL and osteoprotegerin (OPG) are important factors in bone remodeling. RANKL plays a role in bone resorption. RANK will bind osteoclast precursors, which activate osteoclasts, and then bone resorption occurs. Meanwhile, OPG inhibits bone resorption by binding to RANKL; thus, it does not bind to RANK [18]. Considering the exact mechanism of cellular and molecular remodeling in hyperglycemia, which is not yet elucidated, this study was expected to provide an overview of the differences in RANKL and OPG expression between hyperglycemia and normal glucose level condition in an animal model. The aim of this study was to investigate the differences of RANKL and OPG expressions immunohistochemically between normoglycemic and hyperglycemic Wistar rats (Rattus Novergicus) during OTM.

\section{Material and Methods}

Study Design

All experimental procedures involving animals were carried out in keeping with animal research: reporting of in vivo experiments (ARRIVE) guidelines to enhance any animal suffering. 
This study was true experimental with post-test group only. The sample was chosen by using the simple blind random sampling, and the minimum sample size formula determined the sample size. We used 32 healthy male Wistar rats (Rattus Novergicus), weighted around 200-250 grams, and aged around 12-20 weeks old. All the rats were caged individually in polycarbonate cages $(0.90 \times 0.60 \times 0.60 \mathrm{~m})$ for a week on a 12-h light/dark cycle at a steady temperature of $25^{\circ} \mathrm{C}$ and humidity of $50 \%$ for acclimatization to compensate their various origins. Animals were fed by using a standard pellet diet with ad libitum tap water and were routinely inspected for food consumption and fecal characteristics. The 32 samples were divided into 2 groups $(\mathrm{n}=16)$ : normoglycemic rats $(\mathrm{N})$ (normal blood glucose $80-120 \mathrm{mg} / \mathrm{dl}$ ) and hyperglycemic rats $(\mathrm{H})(>250 \mathrm{mg} / \mathrm{dl})$ induced with Streptozotocin (Sigma Aldrich Inc., St. Louis, MO, USA) at the dose of $30 \mathrm{mg}$ in PBS injection intraperitoneally. In rats, hyperglycemic condition was confirmed if the blood sugar levels $\geq 250 \mathrm{mg} / \mathrm{dL}$ checked using Accucheck (EasyTouch GCU, Bioptik Technology Inc., Taiwan) [5].

Prior to performing the experimental procedure, rats were anesthetized with rodent anesthesia (160095, Kepro ${ }^{\mathrm{TM}}$, Netherlands) with the dose of $30 \mathrm{mg} / \mathrm{kg}$ body weight and xylazine $\left(160096, \mathrm{Xyla}^{\mathrm{TM}}\right.$, Netherlands) at the dose of $5 \mathrm{mg} / \mathrm{kg}$ body weight applied intramuscularly on the gluteus muscle during the installation of the orthodontic appliance in their mouth. Nickel Titanium (NiTi) closed coil spring (American Orthodontics, Sheboygan, WI, USA) was mounted between maxillary first molar and the incisors with the light force $10 \mathrm{gf} / \mathrm{mm}^{2}$ for OTM application (Figure 1). Animal studies were terminated on days 1, 3, 6 and 9, respectively. All samples were sacrificed by rodent anesthesia $(60 \mathrm{mg} / \mathrm{kg}$ bw of ketamine and xylazine $3 \mathrm{mg} / \mathrm{kg}$ bw). Rat's premaxilla were dissected and placed in 10\% formalin for four days. After the fixation, the springs were removed, and the premaxillae were decalcified with $5 \%$ nitric acid for two days. The decalcified premaxillae were fixed again in the same manner for another three days. The samples underwent tissue processing according to the previous method $[12,16]$.
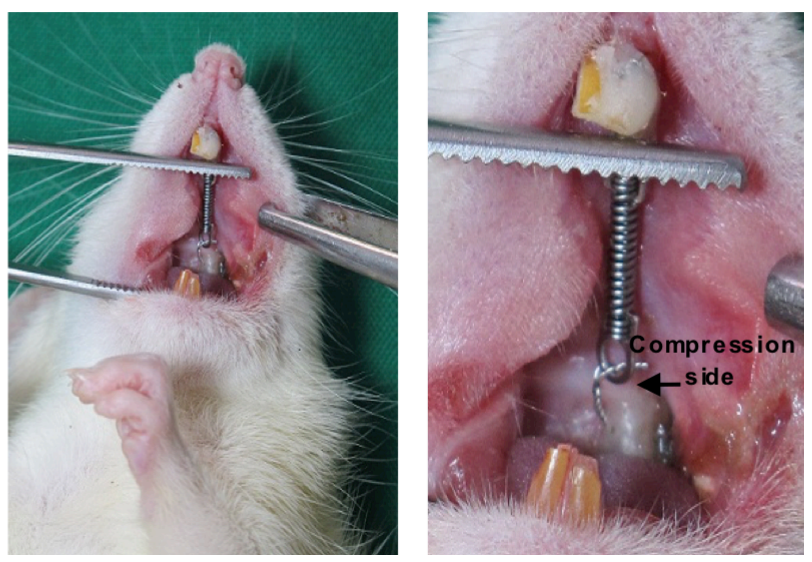

Figure 1. The orthodontic tooth movement in rats was delivered by using NiTi closed coil spring.

Samples were then examined by immunohistochemical staining by an indirect technique using a 3.3'diaminobenzidine stain kit (DAB) (Pierce ${ }^{\mathrm{TM}}$ DAB Substrate Paint Kit 34002, Thermo Fisher Scientific Inc, Waltham, MA, USA) and antibodies (Abcam plc, Cambridge, United Kingdom) which were monoclonal antibody anti-RANKL antibody [C1] (ab239607) and polyclonal antibody anti-osteoprotegerin (OPG) antibody (ab203061). RANKL and OPG were examined in the compression side of OTM, the mesial of left maxillary molar. Next, the cell was ready for microscopy analysis. All these measurements were done by two blinded observers in 5 different visual fields using Nikon H60oL light microscope (Nikon Corp. Tokyo, Japan) 
at 400x magnification with a 300 megapixels Fi2 DS digital camera and image processing software from Nikon Image System (Nikon Corp. Tokyo, Japan) [12,16].

Data Analysis

The data were analyzed by Statistical Package for the Social Sciences 20.0 software (SPSS for Windows, SPSS, Chicago, USA). Descriptive statistics were given as means and standard deviation (SD). Oneway Analysis of Variance (ANOVA) and Tukey Honest Significant Difference (HSD) for post hoc $(\mathrm{p}<0.05)$ were performed based on Shapiro-Wilk and Levene's test $(\mathrm{p}>0.05)$ to compare the osteoclast number and RANKL expression between groups.

Ethical Aspects

Ethical clearance was obtained from the Research Ethics Committee of the Faculty of Dental Medicine, Airlangga University, Surabaya, Indonesia (136/KKEPK.FKG/IX/2014).

\section{Results}

In this study, RANKL expression was observed in the normoglycemic group (N) and the hyperglycemic group (H). RANKL expression was observed in the osteoblast of alveolar bone in periodontal tissue of each study group (Figure 2 ).

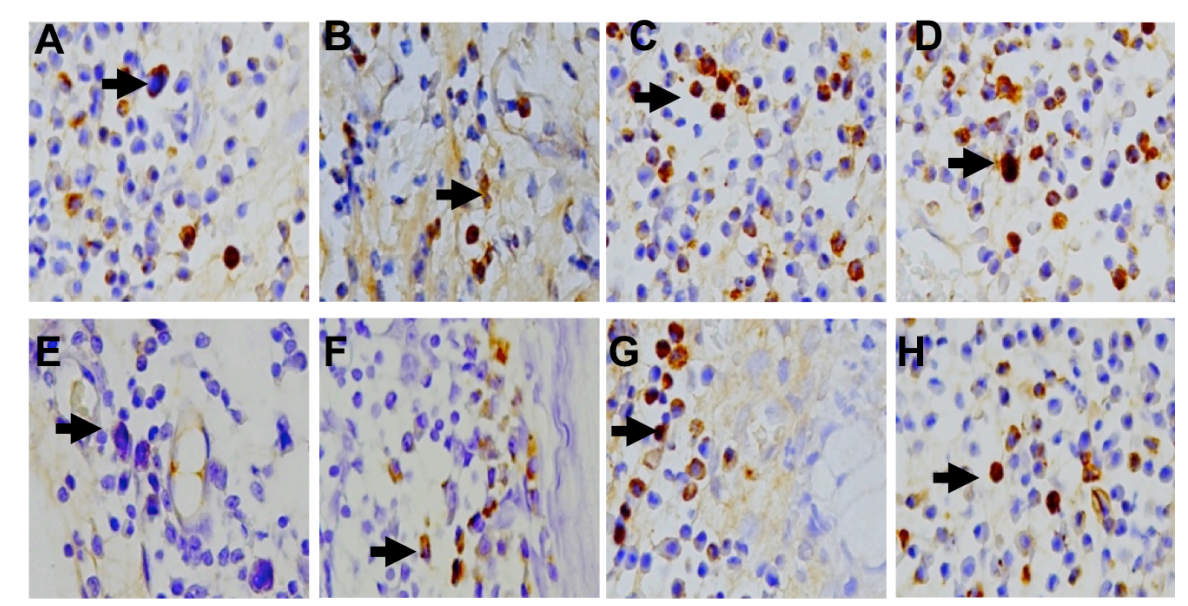

Figure 2. The immunohistochemistry result showed a positive expression (brown color) of RANKL in osteoblast of alveolar bone in the periodontal tissue (black arrow) with 400x magnification by using a light microscope. A. H1; B. H3; C. H6; D. H9 in the hyperglycemic group and in the normoglycemic group: E. N1; F. N3; G. N6; H. N9.

The mean results of RANKL expression in the hyperglycemic group were higher compared to the normoglycemic group (N). RANKL expression in the normoglycemic group has increased on day 3 (N3), and day 6 (N6) then decreased on day 9 (N9). Whereas, in the hyperglycemic group (H), RANKL expression has continued to increase from day $1(\mathrm{H} 1)$ to day 9 (H9), respectively. The highest mean value of RANKL expression in the normoglycemic group was found on day $6(\mathrm{~N} 6)$ and the lowest mean happened on day 1 (N1). As for the hyperglycemic group, the highest expression of RANKL is found in day 9 (H9), and the lowest mean occurs on day 1 (H1). Based on the data obtained, One-way ANOVA was performed and the result showed a significant difference between $\mathrm{N}$ groups and $\mathrm{H}$ groups ( $\mathrm{p}=0.001)$. To find out in detail which group was significantly different, the Tukey HSD test was done. The analysis showed that there were significant 
differences in RANKL expression between the experimental groups on days 1 (P1) and 9 (P9) (p <0.05) (Table $1)$.

Table 1. The mean and standard deviation of RANKL expression between groups.

\begin{tabular}{clcc}
\hline Days & \multicolumn{1}{c}{ Groups } & Mean (SD) & p-value \\
\hline 1 & Normoglycemic 1 & $4.75 \pm 1.500$ & $0.002^{*}$ \\
& Hyperglycemic 1 & $11.00 \pm 1.633$ & \\
3 & Normoglycemic 3 & $11.25 \pm 2.875$ & 0.145 \\
& Hyperglycemic 3 & $15.00 \pm 2.161$ & \multirow{2}{*}{1.000} \\
6 & Normoglycemic 6 & $15.75 \pm 1.258$ & \multirow{2}{*}{$0.001^{*}$} \\
& Hyperglycemic 6 & $16.25 \pm 1.500$ & \\
\hline
\end{tabular}

Tukey Honest Significant Difference; *Statistically Significant.

Furthermore, OPG expression was found positively expressed in the osteoblast of alveolar bone in each group (Figure 3). The mean results of OPG expression in the hyperglycemic group are lower compared to the normoglycemic group. OPG expression in the normoglycemic group decreased on day 3 (N3) and day 6 (N6) then increases in day 9 (N9). Whereas, in the hyperglycemic group (H), OPG expression was decreased. The highest mean value of OPG expression in the normoglycemic group was found on day 1 (N1). Meanwhile, the lowest mean of OPG expression occurred on day 6 in the normoglycemic group (N6). As for the hyperglycemic group, the highest mean of OPG expression was found in day 1 (H1). In addition, the lowest OPG expression was discovered on day 9 in the hyperglycemic group (H9). Based on the data obtained, Oneway ANOVA was performed, the result showed a significant difference between the normoglycemic and hyperglycemic groups. The same as RANKL expression, in finding out in the detail which group was significantly different, the Tukey HSD test was done. The analysis showed that there were significant differences in OPG expression between groups on day 1, 3, and $9(\mathrm{p}<0.05)$ (Table 2$)$.
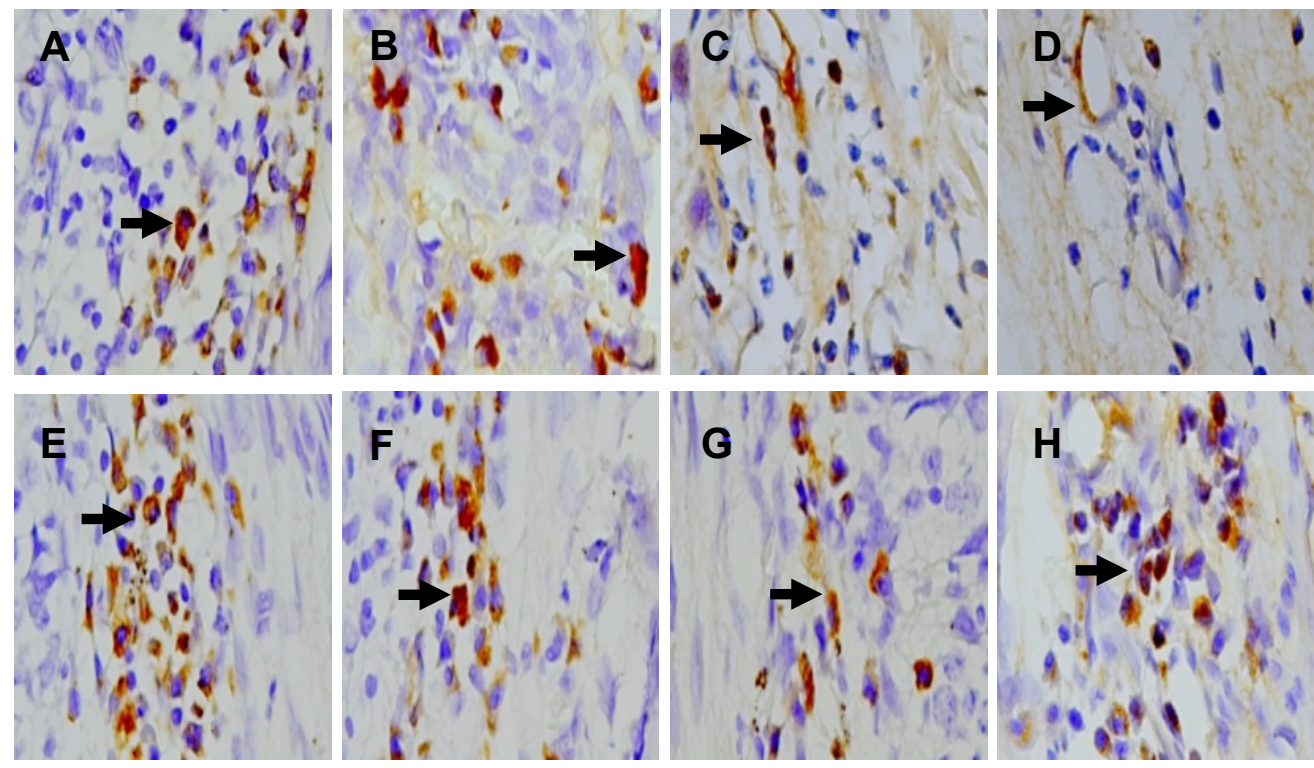

Figure 3. The immunohistochemistry result shows a positive expression (brown color) of OPG in osteoblast of alveolar bone in the periodontal tissue (black arrow) with 400x magnification using a light microscope. A. H1; B. H3; C. H6; D. H9 in the hyperglycemic group and in the normoglycemic group: E. N1; F. N3; G. N6; H. N9. 
Table 2. The mean and standard deviation of OPG expression between groups.

\begin{tabular}{|c|c|c|c|}
\hline Days & Groups & Mean (SD) & p-value \\
\hline \multirow[t]{2}{*}{1} & Normoglycemic 1 & $18.00 \pm 1.826$ & $0.008^{*}$ \\
\hline & Hyperglycemic 1 & $13.50 \pm 2.646$ & \\
\hline \multirow[t]{2}{*}{3} & Normoglycemic 3 & $14.25 \pm 1.258$ & $0.001^{*}$ \\
\hline & Hyperglycemic 3 & $7.25 \pm 1.708$ & \\
\hline \multirow[t]{2}{*}{6} & Normoglycemic 6 & $9.25 \pm 1.258$ & 0.064 \\
\hline & Hyperglycemic 6 & $5.75 \pm 0.957$ & \\
\hline \multirow[t]{2}{*}{9} & Normoglycemic 9 & $13.75 \pm 0.957$ & $0.001^{*}$ \\
\hline & Hyperglycemic 9 & $2.25 \pm 0.957$ & \\
\hline
\end{tabular}

Tukey Honest Significant Difference; *Statistically Significant.

\section{Discussion}

The success of OTM depends on the balance of alveolar bone remodeling process that consisted of bone resorption in the compression side and bone resorption in tensile side in which hyperglycemia can inhibit this process. STZ successfully induced the hyperglycemia condition in rats. The rat with hyperglycemic condition confirmed with the blood sugar levels $\geq 250 \mathrm{mg} / \mathrm{dL}$. Previous studies also support our study that mentioned STZ could be used to induce hyperglycemic conditions in rats $[5,7]$.

In this study, RANKL and OPG were examined in the compression side of OTM in the mesial of left maxillary molar (Figure 1). In the hyperglycemic group, there was an increase in RANKL expression on day 3 (H3) and day 6 (H6) compared to day 1 (H1), then continued to increase on day 9 (H9). The increased RANKL expression due to the force of OTM pressure leads to cellular feedback characterized by the increased proinflammatory cytokines, which stimulates RANKL expression [18].

RANKL will bind to RANK in the osteoclast precursors, which triggers osteoclast differentiation and proliferation, activating the osteoclasts. Mature and active osteoclasts will lead to bone resorption [18-20]. As soon as the force of OTM pressure is applied, the inflammatory cells, osteoclasts and osteoblast progenitors begin to appear. This phase lasts between 24 hours to 2 days as the initial stage of tooth movement in the socket. Meanwhile, osteoclasts are first discovered in the area afflicted by pressure during 36-72 hours after OTM [21-23].

Previous studies stated that RANKL expression should decrease on day 7, followed by an increased OPG expression due to the reduced OTM force in an animal model [20,23]. Meanwhile, in this study, RANKL expression continued to increase and OPG expression decreased until day 9 in the hyperglycemic group. Based on the results in this study, it reveals that there are differences in RANKL expression between groups. Whereas, there is a significant increase in RANKL expression in the hyperglycemic groups on day 1 and 9 (H1 and H9). There is no any decreased RANKL expression on day 9 in the normoglycemic group (N9). The increased RANKL expression is caused by hyperglycemia condition, which can enhance the production of proinflammatory cytokines and the increased RANKL expression plays an essential role in osteoclast proliferation and differentiation [24].

In this study, we found that OPG expression in the hyperglycemic group decreased on day 3 (H3) and day 6 (H6), compared to day 1 (H1), then decreased on day 9 (H9). The increased production of proinflammatory cytokines causes decreased OPG expression under hyperglycemic conditions during the OTM, which can inhibit the OPG expression [18]. The decreased OPG expression on day 9 in hyperglycemic rats with OTM (H9) is led by decreased cytokine production. OPG will inhibit RANKL binding with RANK in osteoclast precursor and stimulate osteoclast apoptosis; thus, it inhibits osteoclastogenesis. The low ratio of RANKL/OPG expression indicates slow tissue regeneration or bone remodeling [18,25]. These results are 
consistent with the in vivo studies using a hyperglycemic mouse model, which mentioned that hyperglycemia condition stimulates the pro-inflammatory cytokine that enhances bone resorption and inhibits bone formation through the enhancement of osteoclast differentiation and proliferation [25].

Some authors reported that the increased mRNA level of Interleukin-1 (IL-1), TNF- $\alpha$, and RANKL and RANK in hyperglycemic conditions could stimulate the maturation of osteoclast that can prolong the duration of alveolar bone resorption and inhibit the bone formation [26,27].

\section{Conclusion}

There was a significant increase in RANKL expression and decrease of OPG expression in hyperglycemic rats as documented immunohistochemically. In addition, a hyperglycemic condition in Wistar rats during OTM might affect alveolar bone remodeling.

\section{Authors' Contributions}

AA D 0000-0003-0433-115X $\begin{aligned} & \text { Conceptualization, Methodology, Investigation, Formal Analysis, Writing - } \\ & \text { Original Draft Preparation, Writing - Review and Editing, Project Administration } \\ & \text { and Funding Acquisition. }\end{aligned}$
ERW (D) 0000-0002-4930-8087
$\begin{aligned} & \text { Methodology, Investigation, Formal Analysis, Writing - Original Draft } \\ & \text { Preparation and Writing - Review and Editing. } \\ & \text { IBN } \quad \text { Donceptualization, Methodology, Investigation, Formal Analysis, Writing - } \\ & \text { Original Draft Preparation and Writing - Review and Editing. }\end{aligned}$
$\begin{aligned} & \text { All authors declare that they contributed to critical review of intellectual content and approval of the final version to be } \\ & \text { published. }\end{aligned}$

\section{Financial Support}

None.

\section{Conflict of Interest}

The authors declare no conflicts of interest.

\section{References}

[1] Evans Jl, Goldfine ID, Maddux BA, Grodsky GM. Oxidative stress and stress-activated signaling pathways: A unifying hypothesis of type 2 diabetes. Endocr Rev 2002; 23(5):599-623. https://doi.org/10.1210/er.2001-0039

[Q] Reichert C, Deschner J, Jäger A. Influence of diabetes mellitus on the development and hyperglycemic of malocclusions - a case report with literature review. J Orofac Orthop 2009; 70(2):160-75. https://doi.org/10.1007/s00056-009-0819-9

[3] Guyton AC, Hall JE. Textbook of Medical Physiology. 11 th ed. Singapore: Elsevier; 2006. pp. 1012-1027.

[4] Alberti KG, Zimmet PZ. Definition, diagnosis and classification of diabetes mellitus and its complications. Part 1: diagnosis and classification of diabetes mellitus provisional report of a WHO consultation. Diabet Med 1998; 15(7):539-53.

[5] Narmada IB, Laksono V, Nugraha AP, Ernawati DS, Winias S, Prahasanti C, et al. Regeneration of salivary gland defects of diabetic wistar rats post human dental pulp stem cells intraglandular transplantation on acinar cell vacuolization and interleukin-10. Pesqui Bras Odontopediatria Clín Integr 2019; 19(1):e5002. https://doi.org/10.4034/pboci.2019.191.144

[6] Rezkita F, Wibawa KGP, Nugraha AP. Curcumin loaded Chitosan nanoparticle for accelerating the post extraction wound healing in diabetes mellitus patient: a review. Research J Pharm Tech 2020; 13(2):1039-42. https://doi.org/10.5958/0974-360X.2020.00191.2

[7] Suciadi SP, Nugraha AP, Ernawati DS, Ayuningtyas NF, Narmada IB, Prahasanti C, et al. The efficacy of human dental pulp stem cells in regenerating submandibular gland defects in diabetic wistar rats (Rattus novergicus). Research J Pharm Tech 2019; 12(4):1573-9. https://doi.org/10.5958/0974-360X.2019.00261.0 
[8] Hisham PNBMB, Narmada IB, Alida A, Rahmawati D, Nugraha AP, Putranti NA. Effects of vitamin D in alveolar bone remodeling on osteoblast numbers and bone alkaline phosphatase expression in pregnant rats during orthodontic tooth movement. J Orofac Sci 2019; 11(2):79-83. https://doi.org/10.4103/jofs.jofs_10_19

[9] Sitasari PI, Narmada IB, Hamid T, Triwardhani A, Nugraha AP, Rahmawati D. East Java green tea methanolic extract can enhance RUNX2 and Osterix expression during orthodontic tooth movement in vivo. J Pharm Pharmacogn Res 2020; 8(4):290-8.

[10] Hermawan RW, Narmada IB, Djaharu'ddin I, Nugraha AP, Rahmawati D. The influence of Epigallocatechin gallate on the nuclear factor associated $\mathrm{T}$ Cell-1 and sclerostin expression in wistar rats (Rattus novergicus) during the orthodontic tooth movement. Research J Pharm Tech 2020; 13(4):1730-4.

https://doi.org/10.5958/0974-360X.2020.00312.1

[11] Nugraha AP, Narmada IB, Sitasari PI, Inayati F, Wira R, Triwardhani A, et al. High mobility group box 1 and heat shock protein-70 expression post (-)-Epigallocatechin-3-gallate in East Java green tea methanolic extract administration during orthodontic tooth movement in wistar rats. Pesqui Bras Odontopediatria Clín Integr 2020; 20:e5347. https://doi.org/10.1590/pboci.2020.040

[12] Narmada IB, Husodo KRD, Ardani IGAW, Rahmawati D, Nugraha AP, Iskandar RPD. Effect of vitamin D during orthodontic tooth movement on receptor activator of nuclear factor Kappa- $\beta$ ligand expression and osteoclast number in pregnant wistar rat (Rattus novergicus). JKIMSU 2019; 8(1):37-42.

[13] Marahleh A, Kitaura H, Ishida M, Shima K, Kishikawa A, Ogawa S, et al. Effect of anti-c-fms antibody on osteoclast formation and proliferation of osteoclast precursor in vitro. J Vis Exp 2019; (145):e59089. https://doi.org/10.3791/59089

[14] Shen WR, Kimura K, Ishida M, Sugisawa H, Kishikawa A, Shima K, et al. The glucagon-like peptide-1 receptor agonist exendin-4 inhibits lipopolysaccharide-induced osteoclast formation and bone resorption via inhibition of TNF- $\alpha$ expression in macrophages. J Immunol Res 2018; 2018:5783639. https://doi.org/10.1155/2018/5783639

[15] Li X, Zhang L, Wang N, Feng X, Bi L. Periodontal ligament remodeling and alveolar bone resorption during orthodontic tooth movement in rats with diabetes. Diabetes Technol Ther 2010; 12(1):65-73. https://doi.org/10.1089/dia.2009.0085

[16] Nareswari RAAR, Narmada IB, Djaharu'ddin I, Rahmawati D, Putranti NAR, Nugraha AP. Effect of vitamin D administration on vascular endothelial growth factor expression and angiogenesis number in orthodontic tooth movement of pregnant Wistar rats. J Postgrad Med Inst 2019; 33(3):182-8.

[17] Inayati F, Narmada IB, Ardani IGAW, Nugraha AP, Rahmawati D. Post oral administration of Epigallocatechin gallate from Camelia sinensis extract enhances vascular endothelial growth factor and fibroblast growth factor expression during orthodontic tooth movement in wistar rats. JKIMSU 2020; 9(1):58-65.

[18] Prahasanti C, Subrata LH, Saskianti T, Suardita K, Ernawati DS. Combined hydroxyapatite scaffold and stem cell from human exfoliated deciduous teeth modulating alveolar bone regeneration via regulating receptor activator of nuclear factor-Kb and osteoprotegerin system. Iran J Med Sci 2019; 44(5):415-21. https://doi.org/10.30476/IJMS.2019.44962

[19] Roberts-Harry D, Sandy J. Orthodontics. Part 11: orthodontics tooth movement. Br Dent J 2004; 196(7):391-4. https://doi.org/10.1038/sj.bdj.4811129

[20] Yamaguchi M. RANK/ RANKL/ OPG during orthodontic tooth movement. Orthod Craniofac Res 2009; 12(2):1139. https://doi.org/10.1111/j.1601-6343.2009.01444.x

[21] D’Apuzzo F, Cappabianca S, Ciavarella D, Monsurrò A, Silvestrini-Biavati A, Perillo L. Biomarkers of periodontal tissue remodeling during orthodontic tooth movement in mice. ScientificWorld J 2013; $2013: 105873$. https://doi.org/10.1155/2013/105873

[22] Nugraha AP, Rezkita F, Putra KG, Narmada IB, Ernawati DS, Rantam FA. Triad tissue engineering: gingival mesenchymal stem cells, platelet rich fibrin and hydroxyapatite scaffold to ameliorate relapse post orthodontic treatment. Biochem Cell Arch 2019; 19(2):3689-93.

[23] Krishnan V, Davidovitch Z. Cellular, molecular, and tissue-level reactions to orthodontic force. Am J Orthod Dentofacial Orthop 2006; 129(4):469.e1-32. https://doi.org/10.1016/j.ajodo.2005.10.007

[24] Kurol J, Owman-Moll P, Lundgren D. Time-related root resorption after application of a normoglycemicled continuous orthodontic force. Am J Orthod Dentofacial Orthop 1996; $110(3): 303-10$.

https://doi.org/10.1016/s0889-5406(96)80015-1

[25] Braga SMG, Taddei SRA, Andrade Jr I, Queiroz-Junior CM, Garlet GP, Repeke CE, et al. Effect of diabetes on orthodontic tooth movement in a mouse model. Eur J Oral Sci 2011; 119(1):7-14.

https://doi.org/10.1111/j.1600-0722.2010.00793.x

[26] Lappin DF, Eapen B, Robertson D, Young J, Hodge PJ. Markers of bone destruction and formation and periodontitis in type 1 diabetes mellitus. J Clin Periodontol 2009; 36(8):634-41.

https://doi.org/10.1111/j.1600-051X.2009.01440.x

[27] Wongdee K, Charoenphandhu N. Osteoporosis in diabetes mellitus: possible cellular and molecular mechanisms. World J Diabetes 2011; 2(3):41-8. https://doi.org/10.4239/wjd.v2.i3.41 